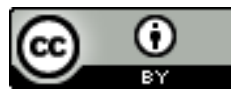

\title{
FORMAÇÃO DO PESQUISADOR E MULTIRREFERENCIALIDADE QUESTÕES EMERGENTES
}

\author{
FORMATION OF RESEARCHERS AND MULTI-REFERENTIALITY \\ EMERGING ISSUES \\ FORMACIÓN DEL INVESTIGADOR Y MULTIRREFERENCIALIDAD \\ CUESTIONES EMERGENTES
}

Luiza Helena Dalpiaz, ${ }^{1}$

\begin{abstract}
RESUMO: No presente texto, o objetivo é apresentar elementos que particularizam meu trabalho na formação do pesquisador, na pós-graduação stricto sensu mestrado acadêmico, considerando a multirreferencialidade como perspectiva epistemológica para a produção de conhecimentos. Esse trabalho refere-se à minha prática como orientadora de mestrando em educação, cuja condição é de estudante/trabalhador em mestrado acadêmico. Essa perspectiva se materializa em um método para problematização de práticas educativas, o qual se fundamenta em uma tríade conceitual e duas noções operativas. $\mathrm{O}$ método se constitui em um caminho em espiral, no qual o sujeito que produz conhecimentos formula uma questão singular que interroga o respectivo campo de conhecimento, por meio de uma metodologia para a construção do problema de pesquisa. Os resultados apontam para um conjunto diversificado de formas de resistência ao modelo hegemônico produtivista da pós-graduação stricto sensu, no Brasil, em diferentes planos: científico, profissional, formativo e existencial. A multirreferencialidade indica possibilidades para se (re)articular campos e sujeitos, saberes e conhecimentos, que comumente encontram-se dissociados ou mutuamente excluídos. Esse é o sentido radical de uma epistemologia do heterogêneo. Do meu ponto de vista, tal perspectiva, (re)atualiza a indissociabilidade da política e da educação, na problematização da interação (ação recíproca) da ação do sujeito singular em uma conjuntura global neoliberal.
\end{abstract}

PALAVRAS-Chave: Formação de pesquisadores. Educação superior. Crise da educação. Educação científica. Prática profissional.

\begin{abstract}
In this text, the objective is to present elements that particularize my job in the formation of researchers, in stricto sensu post-graduation courses academic master's degree, considering the multireferentiality as epistemological perspective for the knowledge production. This work refers to my practice as a master's degree students' advisor, whose condition is student/worker in academic master's degree. This perspective is materialized in a method for the problematization of educational practices, which is based on a conceptual triad and two operative notions. The method is a winding way, in which the subject who produces knowledge formulates a unique issue that questions the respective knowledge field, through a methodology for the construction of the research problem. The results point to a diverse set of ways of resistance to the productivist hegemonic model of the stricto sensu post-graduation, in Brazil, in different plans: scientific, professional, formative, and existential. The multi-referentiality indicates possibilities to (re)articulate fields and subjects, knowledge and insights, which are commonly found dissociated or mutually excluded. This is the radical sense of an epistemology of the heterogeneous. From my point of view, such perspective (re)updates the indissociability of the policy and the education, on the problematization of the interaction (mutual action) of the unique subject's action in a neoliberal global scenario.
\end{abstract}

KEYWORDS: Formation of researchers. Higher education. Crisis of the education. Scientific education. Professional practice.

RESUMEN: En el presente texto, el objetivo es presentar elementos que particularizan mi trabajo en la formación del investigador en el posgrado stricto sensu magister académico, considerando a multirreferencialidad como

Submetido em: 09/05/2018 - Aceito em: 12/06/2018 - Publicado em: 03/07/2018

\begin{tabular}{l|l|l|l|l} 
(C) Rev. Inter. Educ. Sup. & Campinas, SP & v.4 & n.3 & p.631-647
\end{tabular}

set./dez. 2018 
perspectiva epistemológica para la producción de conocimientos. Este trabajo se refiere a mi práctica como orientadora de maestría en educación, cuya condición es de estudiante/trabajador en la maestría académica. Esta perspectiva se materializa en un método para problematización de prácticas educativas, lo cual se fundamenta en una tríade conceptual y dos nociones operativas. El método se constituye en un camino en espiral, en el cual el sujeto que produce conocimientos formula una cuestión singular que interroga el respectivo campo de conocimiento, por medio de una metodología para la construcción del problema de investigación. Los resultados apuntan para un conjunto diversificado de formas de resistencia al modelo hegemónico productivista del pos grado stricto sensu, en Brasil, en diferentes planos: científico, profesional, formativo y existencial. La multirreferencialidad indica posibilidades para (re)articular campos y sujetos, saberes y conocimientos, que comúnmente se encuentran disociados o mutuamente excluidos. Este es el sentido radical de una epistemología de lo heterogéneo. Desde mi punto de vista, tal perspectiva, (re)actualiza el carácter inseparable de la política y de la educación, en la problematización de la interacción (acción recíproca) de la acción del sujeto singular en una coyuntura global neoliberal.

PAlABRAS ClAVE: Formación de investigadores. Educación superior. Crisis de la educación. Educación científica. Práctica profesional.

\section{INTRODUÇÃO}

No Brasil, a pós-graduação strictu sensu (mestrado e doutorado) se constitui no locus para a formação do pesquisador ${ }^{2}$. Conforme Saviani (2010, p.35), “o elemento definidor da pósgraduação stricto sensu é a pesquisa, a qual determina o objetivo a ser alcançado para o qual o ensino concorre como uma mediação destinada a dispor e garantir os requisitos para o desenvolvimento da pesquisa". No Brasil, as universidades se constituem no locus hegemônico da produção científica. Nesse contexto, a formação do pesquisador é indissociável da produção de conhecimentos.

Conforme Hostins (2006, p. 142), “o mais forte redirecionamento vivenciado pela universidade brasileira, entre os anos de 1980 e 1990, foi o da transição de seu status de identidade pública - própria do Estado do Bem Estar - para o de identidade mercantil própria do Estado empresarial". Essa mudança de perspectiva, econômica e política, caracterizada pelos cânones e pelos parâmetros neoliberais, corresponde a orientações internacionais para as políticas educativas: "revelam um alinhamento preciso às orientações de agências internacionais como a UNESCO e o Banco Mundial que exercem um papel decisivo na legitimação dos discursos da agenda de transformação" (HOSTINS, 2006, p.144).

Tais orientações repercutiram diretamente na (re)organização da formação acadêmica da pósgraduação, por meio de um conjunto estruturante e diversificado de modificações, tais como: "a diminuição do tempo de certificação, a redução do número de bolsas e de seu tempo de duração, a redefinição do mestrado com o privilegiamento do doutorado, a vinculação de teses e dissertações a projetos de pesquisa institucional" (HOSTINS, 2006, p.144). Nesse

\footnotetext{
${ }^{2}$ Neste texto não problematizo questões de gênero, por essa razão trabalho com uma escrita em termos genéricos e sem flexões.

\begin{tabular}{|l|l|l|l|l|l|}
\hline C Rev. Inter. Educ. Sup. & Campinas, SP & v.4 & n.3 & p.631-647 & set./dez. 2018 \\
\hline
\end{tabular}
}


período, outras mudanças também contribuíram para a recomposição da base institucional e dos rumos da pós-graduação, no Brasil: “a expansão do sistema nacional de pós-graduação, a diversificação do modelo vigente de pós-graduação de modo a atender também ao meio profissional, as mudanças no processo de avaliação, a implantação do portal de periódicos e inserção internacional" (HOSTINS, 2006, p. 146).

Em consequência das metamorfoses instituídas "passa-se a exigir mais produtividade com tanta pressão que, gradativamente, essa ganha o epíteto de 'produtivismo', denominação com características negativas de um processo no qual a tendência é a quantidade subsumir a qualidade". O referido termo contempla "a quantidade de publicações, a pressão para publicar, os meios para tal e as estratégias lícitas, e outras nem tanto, para a "produção" (ZUIN, BIANCHETTI, 2015, p.731; 738).

Oliveira (2015, p.360) observa que o pós-graduando necessita estabelecer "objetos de estudo mais limitados, restritos e que possam ser executados no tempo estabelecido para o curso". Tais exigências são fruto de uma formação "com pouco tempo para pesquisa, leituras, orientações, o que pode resultar no pouco amadurecimento do novo pesquisador, na menor autonomia intelectual, na realização de pesquisas que parecem sempre inacabadas". Ao analisar consequências do crescimento exponencial da pós-graduação nas últimas décadas, em uma entrevista Dalila de Oliveira constata que "as políticas de avaliação têm estimulado um produtivismo que acaba sendo traduzido em repetições e muita retórica em certas áreas, o que empobrece em muito o campo científico" (CUNHA, MENDES, 2015, p.407).

No presente texto, o objetivo é apresentar elementos que particularizam meu trabalho na formação do pesquisador, na pós-graduação stricto sensu mestrado acadêmico ${ }^{3}$, considerando a multirreferencialidade como perspectiva epistemológica para a produção de conhecimentos. Nos termos de Saviani (2002, p.153), entendo que a função do mestrado é a "iniciação à formação do pesquisador"4 . Na perspectiva de Bourdieu (2005, p.61), entendo a orientação como o lugar no qual o orientador estabelece certas condições práticas para que o orientando construa seu habitus científico, ou seja, se aproprie de um modus operandi e desenvolva uma "disposição incorporada" para a atividade racional que é própria ao trabalho científico.

Considerando que esse trabalho é fruto da interlocução e da cooperação entre orientadora e orientandos/estudantes trabalhadores, do ponto de vista de orientando se colocam duas

\footnotetext{
${ }^{3}$ Hostins (2006) mostra a tensão presente no campo da pós-graduação entre as funções acadêmica e profissional, em um contexto marcado pelos preceitos neoliberais.

${ }^{4}$ Saviani (2002, p. 153-154) faz uma distinção que entendo fundamental para a prática docente, discernimento que fui construindo empiricamente no meu trabalho: "o vetor principal dos cursos de graduação é a formação profissional e não a formação de pesquisadores". Em consequência, a iniciação científica na graduação "teria antes a finalidade de familiarizar o aluno (o futuro profissional) com os processos e os procedimentos da investigação científica".
} 
questões interligadas: como construir um problema de pesquisa a partir da prática profissional? $\mathrm{O}$ que particulariza um problema de pesquisa que emerge da prática profissional, em um mestrado acadêmico?

Do ponto de vista da orientadora emergem dois problemas associados. De um lado, uma tensão epistemológica, pois meu ponto de vista científico, formado no cenário acadêmico francês e no campo da educação, para além da simples repetição, ou da reprodução mecanicista, necessitou ser "traduzido" para tornar-se pertinente no contexto profissional e acadêmico no Brasil. Ao mesmo tempo, uma tensão política e organizacional, pois a construção de um programa de pesquisa, autoral e consistente, individual e coletivo, demanda um processo de trabalho e uma temporalidade opostos às prescrições e aos condicionamentos do produtivismo.

O presente texto está organizado em dois segmentos. No primeiro, apresento elementos epistemológicos e teóricos do método para a problematização de práticas educativas, com o qual trabalho, para a formação do pesquisador; o método se fundamenta em uma tríade conceitual e duas noções operativas. No segundo, caracterizo questões e procedimentos metodológicos que materializam o referido método e particularizam a formação do pesquisador, em minha prática como orientadora de mestrando em educação, cuja condição é de estudante/trabalhador em mestrado acadêmico.

\section{MULTIRREFERENCIALIDADE E CRISE DO PRATICANTE}

Tendo em vista apresentar brevemente algumas particularidades da noção de multirreferencialidade, tomo como ponto de referência a conferência ministrada por Guy Berger, no Brasil, em novembro de $2016^{5}$. O tema, então, abordado foi a atualidade e a pertinência da referida noção, no campo das ciências da educação (BERGER, 2016). A conferência consistiu em homenagem à obra de Jacques Ardoino (1927-2015), autor francês que formulou tal ideia. Berger e Ardoino cultivaram intensa e sistemática cooperação intelectual e acadêmica, desde 1972.

Para Berger (2016, p.1), a origem da noção evidencia a posição epistemológica formulada por Ardoino: a "multirreferencialidade não nasceu de uma reflexão sobre as ciências da educação, mas ela nasceu de uma reflexão sobre a educação enquanto prática efetiva para a formação e a intervenção junto a adultos". Para Ardoino (1977, p. 11), "a educação é uma prática inerente a todo processo civilizador. Explícitas ou implícitas, suas finalidades, necessariamente contraditórias, interessam ao mesmo tempo à perpetuação de uma tradição

${ }^{5}$ As traduções dos textos, do francês para o português, foram por mim realizadas.

\begin{tabular}{l|l|l|l|l|} 
(C) Rev. Inter. Educ. Sup. & Campinas, SP & v.4 & n.3 & p.631-647
\end{tabular} set./dez. 2018 
estabelecida $e$ à possibilidade de um devir diferente". Conforme Berger (2016, p.9), Ardoino sempre considerou a prática enquanto práxis, ou seja, "a ação de um sujeito se transformando ao transformar o mundo".

A noção de multirreferencialidade emerge de um longo caminho, desde o início dos anos 1960, no qual Ardoino trabalhou no entrecruzamento entre distintos lugares e funções profissionais, diferentes espaços e dispositivos educativos, considerando campos disciplinares diversos, tanto das ciências humanas quanto das ciências sociais aplicadas. A sua questão de fundo foi sempre pragmática, da ordem do fazer, operando na indissociabilidade entre educação e política (BERGER, 2016). Para Ardoino (1977, p.241) "todo projeto educativo [...] expressa necessariamente uma posição ideológica, mesmo, e acima de tudo, pretendendose apolítico. Ele supõe efetivamente escolhas, opções, a tradução de uma visão de mundo, e, em consequência, de um projeto de sociedade".

Ardoino elaborou e desenvolveu um modelo de inteligibilidade de situações educativas. Nesse modelo abordava a complexidade da realidade por meio da distinção e da articulação de cinco perspectivas: centradas em pessoas, em inter-relações; centradas no grupo, na organização, na instituição (ARDOINO, 1977). No início dos anos 1990 reformulou a noção de multirreferencialidade, termo já abordado em suas produções das décadas anteriores:

\begin{abstract}
Assumindo plenamente a hipótese da complexidade, ou mesmo da hypercomplexidade, da realidade a respeito da qual interroga-se, a abordagem multirreferencial propõe uma leitura plural de seus objetos (práticos ou teóricos), sob diferentes ângulos, que implicam tanto visões específicas quanto linguagens, apropriadas às descrições necessárias, em função de sistemas de referência distintos, supostos, reconhecidos explicitamente não redutíveis uns aos outros, ou seja, heterogêneos (ARDOINO, 1993, p.15).
\end{abstract}

Para Ardoino (1993, p.19, grifo meu) "a exuberância, a abundância, a riqueza, das práticas sociais" sinalizam para limites "de sua análise clássica, por meio da decomposição-redução". Esse é o motivo que leva, então, "à reabilitação contemporânea do termo complexidade". A complexidade não é uma propriedade ou uma característica do objeto/problema de pesquisa, trata-se de um tipo de olhar (hipótese) com o qual o pesquisador interroga a prática educativa (ARDOINO, 1993). Para esse autor,

[...] a decomposição abstrata ou concreta, por exemplo a dissecação do organismo vivo, leva sempre à evaporação, ao desaparecimento de propriedades e de características as mais específicas e as mais globais do objeto de tais investigações, a vida, a existência, a consciência [...] Quaisquer que sejam os determinismos que condicionam e podem explicar seus modos de funcionamento, o ser humano tem um próprio (auto) poder de negação, de contra estratégia que lhe dá, pelo menos em parte, a inteligência desses determinismos e uma certa capacidade de aí reagir, de aí se adaptar, senão de lhes fazer oposição ou de transformá-los (ARDOINO, 2000, p.256). 
A tensão entre determinismo e transformação indica a complexidade do organismo vivo. Em consequência, essa tensão sinaliza a necessidade de uma leitura plural da realidade, tendo em vista produzir uma ruptura com recorrentes visões reducionistas. A realização dessa leitura supõe selecionar referenciais pertinentes, os quais estão condicionados, ao mesmo tempo, pelas características próprias ao objeto de investigação, assim como pelo repertório (existente e a construir) do sujeito (individual e/ou coletivo) que produz conhecimentos (ARDOINO, 1993). Em outros termos, trata-se de instaurar possibilidades de inteligibilidade inelutavelmente (de)limitadas.

Esse trabalho exige cuidado e rigor epistemológicos, os quais se diferenciam da rigidez formal e do ecletismo simplificador. Nos termos de Ardoino (1993) trata-se de um trabalho, ao mesmo tempo, de poliglota e de bricolagem. Ou seja, por um lado, cabe ao pesquisador desenvolver condições de escuta e de interlocução em relação a linguagens distintas e pertinentes a selecionar. Ao mesmo tempo, para além de uma simplificação depreciativa, é tarefa do pesquisador diferenciar e articular referenciais diferentes, evidentes e emergentes, que sejam significativos para realizar uma (re)composição de sentidos cuja plasticidade constitui um devir inelutável.

Conforme Ardoino (1993, p.30), "novos referenciais sempre poderão aí ser acrescentados sem a vã ambição de totalidade [no sentido de uma explicação completa]. Também não se trata de elaborar um ponto de vista (mítico) de todos os pontos de vista”. Nos termos de Berger, "a multirreferencialidade é uma forma de luto do saber total e de uma síntese de todos os saberes" (BERGER, MUTUALE, 2012, p.93).

Ardoino não operava no sentido "do conhecido para o desconhecido. Ele se deixa invadir pelo desconhecido e logo reflete" sobre tal emergência. Em consequência, "trata-se de incluir no trabalho da razão, a função maior da surpresa, a função maior do inesperado". Nessa perspectiva, a produção de conhecimentos caracteriza-se "muito mais por uma abordagem reflexiva sobre práticas", ato que contém potencialmente a possibilidade da descoberta do/sobre o (des)conhecido (BERGER, 2016, p.7).

$\mathrm{O}$ pensamento multirreferencial leva à produção de um conhecimento que evidencia a pluralidade de sentidos, seja pela diversidade de fontes de referências de idéias; seja pela multiplicidade de sujeitos (individuais e/ou coletivos) implicados na cena analisada instaurando, então, diferentes pontos de vista; seja pela (re)elaboração contínua do sentido da práxis, no tensionamento entre alteridade e temporalidade. Em outros termos, trabalhar nessa perspectiva significa, em ato, suportar a presença e articular diferentes elementos cujas estrutura e função são radicalmente distintas.

[...] a multirreferencialidade, em consequência, é muito mais nessa rearticulação não de campos disciplinares diferentes, mas de um triplo trabalho sobre o saber, sobre a 
construção de si e sobre a construção do mundo e do social que é o político. A verdadeira multirreferencialidade de Jacques não é uma multirreferencialidade que seria uma teoria particular de epistemologia plural, mas muito mais uma epistemologia do heterogêneo, quer dizer, da rearticulação de campos que, normalmente, são totalmente separados e que ele passou seu tempo a tentar não de unificá-los, mas de articulá-los entre si (BERGER, 1999, p.39, eu sublinho).

Para problematizar a formação do pesquisador articulo a multirreferencialidade a duas outras perspectivas científicas, formando assim uma tríade de referências indissociáveis. Conforme mostrarei a seguir, com essa tríade trata-se de construir uma epistemologia do heterogêneo por meio da parceria entre praticantes e pesquisadores para analisar "em ato" práticas educativas.

Nos termos da análise institucional socioanalítica, a instituição "não é uma 'coisa' (versão sociológica) nem um fantasma (versão psicológica) mas um processo: o movimento de forças históricas fazendo e desfazendo as formas" sociais (LOURAU, 1978, p.69). A instituição se constitui em um campo de tensões, entre forças instituídas (estabelecidas e conservadoras) e forças instituintes (dinâmicas e transformadoras), do qual emerge a institucionalização (estabilização momentânea) da forma social. Do indivíduo ao Estado, todas as formas sociais são uma instituição. A análise institucional indaga relações de poder e relações com o saber (LOURAU, 1970). A "análise em situação" trata de "decifrar as relações que os indivíduos e os grupos mantêm com as instituições” (LOURAU, 1970, p. 267). Nesse sentido, provoca a emergência do não saber (o invisível, o não dito, o oculto, o escotoma, o inconsciente) de sujeitos implicados na situação educativa analisada (AUTHIER; HESS, 1981).

O modelo de múltiplas trajetórias para avaliação de políticas sociais coloca em relação fatos e discursos, traçando trajetórias de diferentes atores presentes, em diversos planos, no tecido social da prática educativa considerada. O objetivo é analisar narrativas singulares para identificar necessidades humanas e demandas sociais, observar interações entre interlocutores, construir hipóteses de mudança e acompanhar o desenvolvimento e os efeitos de ações inovadoras. Esse modelo supõe a construção de dispositivos participativos de pesquisa-formação, que promovam a parceria entre pesquisadores e praticantes, para produzir conhecimentos (ZECCA, 1989).

Um ponto de convergência dessas três referências consiste na possibilidade para a produção de uma ruptura epistemológica, condicionada à mudança de lugar do sujeito que produz conhecimentos: o sujeito, individual ou coletivo, tradicionalmente dissociado do problema/objeto que investiga, passa a problematizar sua prática reconhecendo-se implicado na trama social que interroga.

A implicação "é um nó de relações; não é 'boa' (uso voluntarista) nem 'má' (uso jurídicopolicial) [...] [está] sempre já lá” (LOURAU, 1990, p.113), ou seja, trata-se de um existente a 
analisar. Como "objeto a ser elucidado", a implicação "se revela como um modo de ser, opaco à consciência e suportado mais do que escolhido [...] constitui um outro modo especial de produção de conhecimentos do qual ela se tornará parte integrante" (ARDOINO, 1983, p.19-20).

O sujeito que analisa sua implicação considera a interação, relação e ação recíproca, entre sujeito-objeto-situação (LOURAU, 1988). Essa análise exige um trabalho paradoxal, entre forças simultâneas e contrárias: aproximação/distanciamento do sujeito, delimitação/complexificação do objeto/problema, subjetivação/objetivação dos conhecimentos. Nos termos de Devereux (1980), a (re)construção do rigor científico supõe um trabalho de elucidação de perturbações que atravessam o pesquisador, o qual é distinto da ilusão de neutralidade, da fantasia de transparência e da aspiração de objetividade da ciência. Em termos epistemológicos, a análise da implicação conduz ao problema da subjetividade como constitutiva do processo para produção de conhecimentos.

Para articular elementos desse conjunto de referências teóricas, trabalho com duas noções operativas - crise do praticante e tensão paradigmática. Dessa forma, estabeleço um princípio organizador do pensamento e um lugar singular a partir do qual o sujeito inicia o processo para produção de conhecimentos. Na origem elaborei a noção de crise do praticante, no campo das ciências da educação, para compreender o sentido do mal-estar presente no percurso do assistente social, no entrelaçamento da formação acadêmica, do exercício profissional e da militância política.

No sentido etimológico, o termo crise, do grego krísis significa "alteração, desequilíbrio repentino; estado de dúvida e incerteza; tensão, conflito" (CUNHA, 1996, p.228). A crise instaura dúvidas, imprevisibilidade e abre um campo de possibilidades, com diferentes tendências: de transgressão e mudança; de (re)acomodação e retorno ao status quo; ou de agravamento da situação inicial. A noção de praticante refere-se ao sujeito que exerce sua prática, em diferentes campos de intervenção (social, educativo, político, terapêutico, científico etc.), em distintas instâncias organizacionais e institucionais.

A crise do praticante é constituída por três elementos entrecruzados e interdependentes: existencial (problemas de identidade profissional, individual e coletiva); político (dificuldades com relações de poder e nas relações com o saber) e científico (conflitos entre teoria e prática). A hipótese é de que a superação da crise supõe que o praticante se torne praticantepesquisador sobre sua própria prática para produzir conhecimentos. Em consequência, subsídios são assim gerados tendo em vista potencialmente contribuir para (re)construção de projetos profissionais, organizacionais e científicos (DALPIAZ, 1994).

A crise do praticante, inicialmente abordada como noção analítica do problema de pesquisa, se tornou uma noção epistemológica em minha prática científica (DALPIAZ, DE LA FARE

\begin{tabular}{l|l|l|l|l|l}
\hline (C) Rev. Inter. Educ. Sup. & Campinas, SP & v.4 & n.3 & p.631-647 & set./dez. 2018
\end{tabular}


2000). O praticante, ao se interrogar sobre sua própria prática, opera o princípio holográfico da complexidade: “[...] o todo está na parte que está no todo" (MORIN, 1986, p. 101). Esse princípio supõe que a pergunta do sujeito singular expressa um problema do respectivo campo de referência, em diferentes níveis complementares de complexidade (DALPIAZ, 2005, 2015). A questão do sujeito caracteriza-se, ao mesmo tempo, como um indício, que sinaliza sentidos implícitos da prática (GINZBURG, 1989), e, em termos institucionalistas, como um analisador, pois permite "[...] revelar a estrutura da instituição, provocá-la, forçá-la a falar" (LOURAU, 1970, p. 283).

O trabalho do praticante para formular sua pergunta singular produz uma tensão paradigmática, ao desvelar a concomitância e o conflito entre tradições e exigências distintas que constituem o sujeito em sua prática, em diferentes instâncias organizacionais e institucionais (DALPIAZ, DE LA FARE, 2000).

A tríade de referências conceituais (multirreferencialidade, análise institucional socioanalítica, modelo de múltiplas trajetórias para avaliação de políticas sociais) e as duas noções operativas (crise do praticante, tensão paradigmática) particularizam o método para problematização de práticas educativas. Método significa caminho, que se inspira em princípios a operacionalizar, e não se reduz a procedimentos formais a repetir ou a reproduzir. $\mathrm{O}$ método refere-se a um conjunto de ideias que estabelecem uma perspectiva e certas condições estratégicas, considerando-se a realização de um percurso para a produção de conhecimentos. Ao princípio recursivo do método corresponde um caminho em espiral, no qual processo é produto e vice-versa na construção de conhecimentos (MORIN, 1986).

$\mathrm{Na}$ sequência, apresento características do trabalho que realizo para a formação do pesquisador, o qual tem como base o método para problematização de práticas educativas.

\section{FORMAÇÃO DO PESQUISADOR: QUESTÕES EMERGENTES}

Em termos multirreferenciais, o termo formação é associado à hipótese do sujeito inacabado, ou seja, o sujeito-autor de seu destino é sempre vir a ser, na emergência da pluralidade de si mesmo, na interação com a diversidade do mundo, na plasticidade de sua prática social. Segundo Ardoino (1977, p.242), a formação implica associação e complementaridade entre "o saber, o saber-fazer e o saber ser e vir a ser".

No presente texto estou considerando elementos emergentes de minha práxis como orientadora de mestrando em educação, cuja particularidade é sua condição de estudante/trabalhador em um mestrado acadêmico. Do meu ponto de vista, entendo que é na própria experiência de orientar, para que o estudante se torne pesquisador, que me formo orientadora. Nos termos de Bourdieu (2005), no mestrado à orientação corresponde a 
responsabilidade por instaurar condições que propiciem a constituição do habitus científico do orientando. Por se tratar da formação à pesquisa de estudante trabalhador se colocam, para mim, duas questões epistemológicas: como construir um problema de pesquisa a partir da prática profissional? O que particulariza um problema de pesquisa que emerge da prática profissional, em um mestrado acadêmico? A seguir, indicarei quatro questões que, entre outras, emergem de minha prática e sinalizam dificuldades que atravessam a formação e a produção de conhecimentos do mestrando trabalhador.

Do ponto de vista da prática profissional, considero que a experiência do praticante é complexa, pois constituída por uma multiplicidade de elementos em interação: sociais, econômicos, políticos, culturais, psicológicos, etc. (MORIN, 1986). Tais elementos se materializam em diferentes planos de intervenção, seguidamente entrelaçados: individuais, grupais, coletivos, organizacionais, comunitários, etc. $\mathrm{O}$ mestrando é marcado pela cultura oral e sua experiência lhe constitui como sujeito (ZECCA, 1989): há muito a contar, a comentar, a se interrogar, a refletir.

Do ponto de vista da prática acadêmica, constato que o praticante apresenta dificuldades na leitura e na interpretação de textos teóricos, assim como na escrita baseada em cânones acadêmicos instituídos. Além disso, no início do mestrado, o estudante apresenta uma visão de mundo e um olhar para a realidade marcados por objetos pré-construídos. "A força do préconstruído está em que, achando-se inscrito ao mesmo tempo nas coisas e nos cérebros, ele se apresenta com as aparências da evidência, que passa despercebida porque é perfeitamente natural” (BOURDIEU, 2005, p.49).

Os objetos pré-construídos têm relação com o senso comum, ou seja, "com representações partilhadas por todos, quer se trate dos simples lugares comuns da existência vulgar, quer se trate das representações oficiais, frequentemente inscritas nas instituições [...] na objectividade das organizações sociais" (BOURDIEU, 2005, p.34). O mundo acadêmico também produz "senso comum douto" (BOURDIEU, 2005, p.48) ao promover formas de simplificação e mesmo banalização de ideias, assim como formas de reprodução mecanicista e mesmo repetição simplista de procedimentos.

Do ponto de vista da implicação do pesquisador, conforme Lourau (1990, p.112), a abordagem da implicação freqüentemente leva a uma "nebulosa ideológica", pois é confundida com termos como: "compromisso, participação, investimento afetivo, motivação, etc". Lourau (1990) propõe o conceito de sobreimplicação para caracterizar elementos que dificultam, disfarçam e mesmo ocultam a implicação do sujeito: o sobretrabalho exigido para a produção da mais-valia, a exploração e a submissão baseadas na alienação, a performance dos círculos de qualidade, o voluntarismo em nome de diferentes causas, o isolamento e o predomínio de uma única perspectiva de análise.

\begin{tabular}{|l|l|l|l|l|l} 
(C) Rev. Inter. Educ. Sup. & Campinas, SP & v.4 & n.3 & p.631-647 & set./dez. 2018
\end{tabular}


No ângulo da sobreimplicação observo, ainda, que o praticante projeta diversas demandas concomitantes e implícitas, a serem supostamente abordadas na formação para se tornar pesquisador: avaliação da política pública, reorientação da prática profissional ou da inserção social, desenvolvimento pessoal, aprendizagem do método científico e expressão da sua originalidade como sujeito individual e coletivo. Na gênese desse conjunto de demandas se encontra o desejo de transformação.

Do ponto de vista da produção científica, em uma perspectiva epistemológica multirreferencial (ARDOINO, 1993) entendo que esse conjunto heterogêneo de dificuldades acima mencionadas produz a exigência, sempre problemática, de distinguir diferentes formas possíveis para a produção de conhecimentos, cuja origem se situa na prática do sujeito que produz conhecimentos. Essa exigência, a meu ver, é condição para estabelecer parâmetros de um rigor que viabilize uma produção científica qualificada, sobre tema emergente da prática, em um mestrado acadêmico.

A título exploratório, de um trabalho a ser conceitualmente desenvolvido, na prática da orientação procuro diferenciar e problematizar, na interlocução com o orientando, distintas posições do sujeito que produz conhecimentos: questionamento pessoal (interrogar-se sobre a finalidade da própria existência), intervenção profissional ou social (produzir modificação na realidade), avaliação da prática ou da política (compreender o sentido da ação empreendida), formação do sujeito (tornar-se outro "em ato"), pesquisa propriamente dita (construir um problema empírico-teórico) (DALPIAZ, 2003).

Conforme indicado no segmento anterior do presente texto, a crise do praticante se constitui em uma noção epistemológica que instaura um lugar singular a partir do qual o sujeito inicia o processo para produção de conhecimentos. A crise é aqui entendida como momento questionador de certezas instituídas. O praticante, ao se interrogar sobre sua própria prática, expressa um problema do respectivo campo de referência.

Minha hipótese para desencadear a orientação é de que o relato inicial do orientando expresso em uma escrita "espontânea" contém pistas, ainda que em filigrana, sobre elementos que compõem a pergunta do sujeito. No começo da orientação, o orientando é provocado a relatar seu percurso formativo e interventivo, assim como se interrogar sobre o caminho até então realizado, por meio de um instrumento chamado texto livre. Em consequência, o questionamento subjetivo, objetivado na escrita, estabelece "em ato" o lugar que instaura o "ponto de partida" do processo para produzir conhecimentos. O texto livre é um instrumento da orientação para trabalhar a análise da implicação do orientando tendo em vista a elaboração do problema de pesquisa. 
$\mathrm{Na}$ orientação, esse trabalho inaugura a metodologia para construção do problema de pesquisa constituída de três momentos distintos, aos quais correspondem respectivos instrumentos investigativos:

- explicitação do problema da prática: análise da implicação do sujeito em relação à sua prática profissional e/ou acadêmica e/ou militante. Instrumento: texto livre;

- formulação do problema teórico: a partir de questões emergentes do texto livre, elaboração de um mapa contextual/conceitual, formado pelas categorias constitutivas do problema da prática. Instrumentos: estudos bibliográficos e documentais; se for o caso, contatos e/ou entrevistas com pesquisadores e/ou outros profissionais com reconhecido saber sobre o problema em pauta;

- complexificação do problema empírico-teórico de pesquisa: realização da (re)formulação e estabelecimento de desdobramentos do problema de pesquisa. Instrumentos: interlocução com pares praticantes no campo empírico, aprofundamento de estudos bibliográficos e documentais.

Para além de uma aparente linearidade, os três momentos sinalizam rumos a explorar, que se entrecruzam e se influenciam mutuamente, na construção do caminho a ser percorrido pelo sujeito que produz conhecimentos (DALPIAZ, 2015). Essa metodologia materializa o método para problematização de práticas educativas, o qual particulariza minha prática singular como orientadora.

Em outros termos, por meio dessa metodologia construo um dispositivo de pesquisaformação tendo em vista, ao mesmo tempo, materialisar/operar o método para problematização de práticas educativas, assim como instaurar condições que propiciem a constituição do habitus científico do orientando. Para Berger, o dispositivo concerne "o encontro entre elementos de tipo intelectual e uma organização ligada a uma maneira de ocupar o espaço, a uma maneira de ocupar a duração" (BERGER, MUTUALE, 2012, p.102).

Nessa forma de pesquisa-formação trata-se de produzir uma ruptura em relação ao lugar do sujeito que produz conhecimentos: da tradicional dissociação entre sujeito e problema/objeto de investigação, o sujeito passa a reconhecer a interação (ação recíproca) entre tais elementos. Outra ruptura a ser produzida é na "conversão do olhar" do pesquisador, ou seja, a formação tem por função propiciar condições para “'dar novos olhos' como dizem por vezes os filósofos iniciáticos” (BOURDIEU, 2005, p.49). 


\section{CONSIDERAÇÕES FINAIS}

No presente texto, o objetivo foi apresentar elementos que particularizam meu trabalho na formação do pesquisador, na pós-graduação stricto sensu mestrado acadêmico, considerando a multirreferencialidade como perspectiva epistemológica para a produção de conhecimentos. Inicialmente apresentei elementos epistemológicos e teóricos do método para a problematização de práticas educativas, com o qual trabalho, para a formação do pesquisador.

$\mathrm{O}$ método se fundamenta em uma tríade conceitual e duas noções operativas. O método se constitui em um caminho em espiral, no qual o sujeito que produz conhecimentos formula uma questão singular que interroga o respectivo campo de pertencimento. Na sequência caracterizei questões e procedimentos metodológicos que materializam o referido método e particularizam a formação do pesquisador, em minha prática como orientadora de mestrando em educação, cuja condição é de estudante/trabalhador em mestrado acadêmico.

No Brasil, as políticas educativas em geral, e em particular a pós-graduação stricto sensu mestrado e doutorado estão marcadas por orientações internacionais que estabelecem cânones, parâmetros e exigências, as quais são fundamentadas no modelo empresarial neoliberal. Esse ambiente se caracteriza por um conjunto complexo de condições e de condicionamentos que instauram um modus operandi produtivista na prática do orientador e do orientando.

Para Dejours (2004, p.33-34), “a evolução contemporânea das formas de organização do trabalho, de gestão e de administração, depois da virada neoliberal, repousa sobre princípios que sugerem, precisamente, sacrificar a subjetividade em nome da rentabilidade e da competitividade". Dejours (2004, p.34) destaca, entre outros, dois princípios: "o recurso sistemático à avaliação quantitativa e objetiva do trabalho", a qual "funciona, sobretudo, como um meio de intimidação e de dominação"; "a individualização e o apelo à concorrência generalizada entre as pessoas, entre as equipes e entre os serviços", os quais "conduzem ao desenvolvimento de condutas desleais entre pares e à ruína das solidariedades".

No entanto, Dejours (2004, p.34) sublinha que a "evolução contemporânea da organização do trabalho não é uma fatalidade". Para esse autor "nenhuma organização [...] nenhum sistema funciona por si mesmo, automaticamente [...] para funcionar, todo sistema tem necessidade não somente da obediência dos homens e das mulheres, mas do zelo destes, isto é, da sua inteligência”.

Conforme Ardoino (1977), a educação abrange duas finalidades contraditórias, que operam nas práticas educativas: determinismo e transformação. Do meu ponto de vista, entendo que o trabalho na formação do pesquisador contém possibilidades, paradoxalmente, para realizar 
formas de resistência ao modelo hegemônico produtivista. Conforme mostrei ao longo do presente texto, tenho procurado desenvolver uma epistemologia do heterogêneo, que se particulariza pelas noções operativas de crise do praticante e tensão paradigmática.

Do ponto de vista científico, a metodologia para a construção do problema de pesquisa cria condições para (re)organizar a relação do sujeito com seu próprio saber, com o conhecimento de autores de referência e, também, com o saber de pares praticantes do campo empírico de origem. Esse trabalho produz, pelo menos em parte, uma ruptura com a simples repetição de noções e de conceitos simplificados pelo senso comum e modismo acadêmicos.

Do ponto de vista profissional, a análise da sobreimplicação do sujeito como caminho para a formulação do problema de pesquisa, leva o mestrando a estabelecer algumas distinções entre diferentes espaços e dispositivos nos quais intervém e dos quais, inicialmente de forma entrelaçada e confusa, emerge seu tema de pesquisa. Esse trabalho leva a estabelecer algumas fronteiras simbólicas entre o espaço acadêmico, o espaço profissional e, se for o caso, o espaço de militância. Essa distinção, por meio de um trabalho de diferenciação, propicia condições para realizar uma produção empírico-conceitual, própria ao espaço acadêmico, que, pelo menos em parte, se diferencia do relato de experiência, do discurso abstrato e desencarnado, da restituição documental, do discurso prescritivo.

Do ponto de vista formativo, o trabalho em parceria orientador e orientando propicia condições para explicitação de saberes estruturalmente diferentes. Por meio de um processo de interlocução, se constrói um tema comum e compartilhado, o qual tem a função de guia e de norte para a caminhada acadêmica, do estudante que se prepara para torna-se pesquisador. Esse processo possibilita estabelecer um espaço de negociação para ajustes em rumos formativos, que se evidenciam necessários no percurso. Essa cooperação produz uma ruptura, tendo em vista formas de alienação, que se materializam na submissão do mestrando a tarefas, encaminhamentos e decisões supostamente inquestionáveis. Por outro lado, trabalhos já em andamento mostram caminhos possíveis para a continuidade da parceria com o mestrando, na condição de egresso, em particular em dispositivos de co-autoria de textos.

Do ponto de vista existencial, trata-se de estabelecer um espaço/tempo regular e sistemático, para que orientador e orientando conversem sobre a prática em comum, própria à formação do pesquisador, em todas as instâncias possíveis e ao longo de todo processo formativo no mestrado. A situação de conversa constrói um ambiente micro social sistemático, de escuta e de autorização, no qual se exercita expressão individual, não julgamento do outro, reflexão compartilhada e debate de ideias. Dessa forma, esse contexto provoca a emergência de necessidades de aprendizagens técnicas, demandas de conhecimentos teóricos, imperativos de protagonismo, desejos de autoria. Simultaneamente, promove a experiência, sempre perturbadora e nunca finalizada, com a desconstrução de posturas autoritárias, visões deterministas, pensamentos monorreferenciais.

\begin{tabular}{l|l|l|l|l|l} 
(C) Rev. Inter. Educ. Sup. & Campinas, SP & v.4 & n.3 & p.631-647 & set./dez. 2018 \\
\hline
\end{tabular}


Para finalizar. A multirreferencialidade indica possibilidades para se (re)articular campos e sujeitos, saberes e conhecimentos, que comumente encontram-se dissociados ou mutuamente excluídos. Esse é o sentido radical de uma epistemologia do heterogêneo. Do meu ponto de vista, tal perspectiva, (re)atualiza a indissociabilidade da política e da educação, na problematização da interação (ação recíproca) da ação do sujeito singular em uma conjuntura global neoliberal.

\section{REFERÊNCIAS}

ARDOINO, Jacques. Les avatars de l'éducation; problématiques et notions em devenir.

Paris: Presses Universitaires de France, 2000. (Éducation et formation; pédagogie théorique et critique)

ARDOINO, Jacques. L'approche multiréférentielle (plurielle) des situations éducatives et formatives. Pratiques de Formation - Analyses. Saint-Denis, n. 25-26, p. 15-41, avr. 1993.

ARDOINO, Jacques. Polysémie de l' implication. In: Revue POUR, Toulouse, n. 88, p. 1922, mar.-avr. 1983.

ARDOINO, Jacques. Éducation et politique; propos actuels sur l'éducation II. Paris: Gauthier-Villars, 1977.

AUTHIER, Michel.; HESS, René. L’analyse institutionnelle. Paris: PUF, 1981. (Que saisje?, 1968)

BERGER, Guy. Da atualidade e pertinência da perspectiva multirreferencial em ciências da educação: homenagem à obra de Jacques Ardoino. Manuscrito de conferência realizada em: (IN)FORMACCE - COLÓQUIO NACIONAL DE ESTUDOS, PESQUISAS E INTERVENÇÕES EM CURRÍCULO E FORMAÇÃO, IV; CObFORMACCE CONFERÊNCIA DO OBSERVATÓRIO AVANÇADO DE CURRÍCULO E FORMAÇÃO, I. 2016, Salvador: Grupo de Pesquisa FORMACCE em Aberto, PPGE/UFBA, 2016, 22p.

BERGER, Guy; MUTUALE, Augustin. Conversations sur l'éducation; s'autoriser à éduquer. Paris: L'Harmattan, 2012. (Éducations et sociétés)

BERGER, Guy. Ardoino et la multiréférentialité. Pratiques de formation, Analyses - "Le devenir de la multiréférentialité; hommage à Jacques Ardoino", Saint-Denis, n. 36, p. 33-40, fév. 1999.

BOURDIEU, Pierre. O poder simbólico. Tradução de Fernando Tomaz. 8.ed. Rio de Janeiro: Bertrand Brasil, 2005.

CUNHA, Antonio Geraldo da. Dicionário etimológico nova fronteira da língua portuguesa. 2.ed. rev. Rio de Janeiro: Nova Fronteira, 1996. 
CUNHA, Myrtes Dias da; MENDES, Olenir Maria. Entrevista - A Pós-Graduação e a pesquisa em Educação: trajetórias percorridas e desafios atuais. Entrevista com Carlos Roberto Jamil Cury e Dalila Andrade de Oliveira. Práxis Educativa, Ponta Grossa, v. 10, n. 2, p. 405-413, jul./dez. 2015. Disponível em:

<http://www.revistas2.uepg.br/index.php/praxiseducativa/article/view/7566/4550>. Acesso em: 11 maio 2017.

DALPIAZ, Luiza Helena. Devenir praticien-chercheur, une possibilite pour le dépassement de la crise des travailleurs sociaux: l'approche d'une assistante sociale. 1994. Thèse (Doctorat en Sciences de l'Éducation)-Département des Sciences de l'Éducation, Université Paris VIII - Vincennes à Saint-Denis, Saint-Denis-France, 1994.

DALPIAZ, Luiza Helena. Método de problematização de práticas sociais e formação profissional. In: SEMINÁRIO INTERNACIONAL DE COMUNICAÇÃO - "DA ALDEIA GLOBAL AO CIBERESPAÇO: AS TECNOLOGIAS DO IMAGINÁRIO COMO EXTENSÕES DO HOMEM: A NOVA ORDEM EM REDE”, 7., 2003, Porto Alegre, RS. Anais. Porto Alegre, RS: PPGCom - Famecos/Pucrs, 2003. CD.

DALPIAZ, Luiza Helena. Método de problematização de práticas sociais e formação profissional. Revista Temas Sociais em ExpreSSão, Frederico Westphalen, v. 4, n.4, p.67$82,2005$.

DALPIAZ, Luiza Helena. Educação permanente e políticas públicas: problematização de práticas e produção de conhecimentos. Roteiro, Joaçaba, v.40, ed. esp., p.173-192, 2015. Disponível em: <http://editora.unoesc.edu.br/index.php/roteiro/article/view/9189/5248>. Acesso em: 05 jan. 2016.

DALPIAZ, Luiza Helena; DE LA FARE, Monica. A pesquisa como problema: elementos de um método de pesquisa-formação no Serviço Social. In: ENCONTRO NACIONAL DE PESQUISADORES EM SERVIÇO SOCIAL - “O SERVIÇO SOCIAL E A QUESTÃO SOCIAL: DIREITOS E CIDADANIA", 7, 2000, Brasília, DF. Anais. Brasília, DF: ABEPSS, 2000.

DEJOURS, Christophe. Subjetividade, trabalho e ação. Revista Produção, São Paulo, v. 14, n. 3, p. 27-34, set./dez. 2004. Disponível em:

<http://www.scielo.br/pdf/prod/v14n3/v14n3a03.pdf>. Acesso em: 15 jun. 2016.

DEVEREUX, Georges. De l'angoisse à la méthode dans les sciences du comportement. Paris, Flammarion, 1980. (Nouvelle bibliothèque scientifique)

GINZBURG, Carlo. Mitos, emblemas, sinais: morfologia e história. Tradução Federico Carotti. São Paulo: Companhia das Letras, 1989.

HOSTINS, Regina Célia Linhares. Os Planos Nacionais de Pós-Graduação (PNPG) e suas repercussões na Pós-graduação brasileira. Perspectiva, Florianópolis, v. 24, n. 1, p. 133-160, jan/jun. 2006. Disponível em: 〈http://www.perspectiva.ufsc.br〉. Acesso em: 14 abr. 2017.

\begin{tabular}{|l|l|l|l|l|l} 
(C) Rev. Inter. Educ. Sup. & Campinas, SP & v.4 & n.3 & p.631-647 & set./dez. 2018 \\
\hline
\end{tabular}


LOURAU, René. Implication et surimplication. Revue du Mauss. Paris, n. 10, p. 110-120, 4. trim. 1990.

LOURAU, René. Le journal de recherche; matériaux d'une théorie de l'implication. Paris: Meridiens Klincksieck, 1988. (Analyse institutionnelle).

LOURAU, René. L’état inconscient. Paris: Minuit, 1978. (Arguments)

LOURAU, René. L’analyse institutionnelle. Paris: Minuit, 1970. (Arguments)

MORIN, Edgar. La méthode 3. La connaissance de la connaissance. Paris: Seuil, 1986. (Points, Essais, 236)

OLIVEIRA, João Ferreira de. A Pós-Graduação e a pesquisa no Brasil: processos de regulação e de reconfiguração da formação e da produção do trabalho acadêmico. Práxis Educativa, Ponta Grossa, v. 10, n. 2, p. 343-363, jul./dez. 2015. Disponível em: $<$ http://www.revistas2.uepg.br/index.php/praxiseducativa/article/view/7138/4546>. Acesso em: 11 maio 2017.

SAVIANI, Dermeval. A pós-graduação em educação no Brasil: pensando o problema da orientação. In: BIANCHETTI, Lucídio; MACHADO, Ana Maria Netto. (Orgs.) A bússola do escrever; desafios e estratégias na orientação de teses e dissertações. Florianópolis: UFSC; São Paulo: Cortez, 2002, p.135-163.

SAVIANI, Dermeval. O dilema produtividade-qualidade na pós-graduação. Nuances: Estudos sobre Educação, Presidente Prudente, SP, ano XVII, v. 17, n. 18, p. 32-49, jan./dez. 2010. Disponível em: <http://revista.fct.unesp.br/index.php/Nuances/article/view/723/736> . Acesso em: 11 maio 2017.

ZECCA, Marine. L'évaluation: outils d'émancipation? In: BACHMANN, Christian. Les savoirs-faire de l'inquiètude et du renouveau: une formation à l'évaluation de l'action sociale. Paris: PROMOFAF, 1989, p.57-59.

ZUIN, Antônio. A. S.; BIANCHETTI, Lucídio. O produtivismo na era do "publique, apareça ou pereça": um equilíbrio difícil e necessário. Cadernos de Pesquisa, São Paulo, vol. 45, n. 158, p. 726-750, dez. 2015. Disponível em: <http://www.scielo.br/pdf/cp/v45n158/19805314-cp-45-158-00726.pdf>. Acesso em: 11 maio 2017.

\section{Sobre a Autora}

\section{${ }^{1}$ Luiza Helena Dalpiaz}

E-mail: 1hdalpiaz@gmail.com

Universidade do Oeste de Santa Catarina - Brasil

Doutora em Ciências da Educação pela University Paris 8 - Vincennes à Saint-Denis [França]

\begin{tabular}{l|l|l|l|l|l} 
(C) Rev. Inter. Educ. Sup. & Campinas, SP & v.4 & n.3 & p.631-647 & set./dez. 2018 \\
\hline
\end{tabular}

